Case report

\title{
Endometrial carcinoma in a single horn of a bicornuate uterus: A case report
}

\author{
Khaled Gaballa $^{\mathrm{a}, *}$, Carla Cicero ${ }^{\mathrm{b}}$, Valerio Gallotta ${ }^{\mathrm{b}}$, Gianfranco Zannoni ${ }^{\mathrm{c}}$, Giovanni Scambia ${ }^{\mathrm{b}}$ \\ a Surgical Oncology, Oncology Center Mansoura University, Mansoura, Egypt \\ ${ }^{\mathrm{b}}$ Gynecologic Oncology, Department of Gynecologic Oncology, Catholic University of the Sacred Heart, Rome, Italy \\ ${ }^{\mathrm{c}}$ Human Pathology, Pathology Department, Catholic University of the Sacred Heart, Rome, Italy
}

\section{A R T I C L E I N F O}

\section{Article history:}

Received 2 April 2018

Received in revised form 27 April 2018

Accepted 30 April 2018

Available online 17 May 2018

\section{Keywords:}

Bicornuate uterus

Endometrial cancer

\begin{abstract}
A B S T R A C T
We discuss the diagnosis and the management of endometrial carcinoma in a single horn of bicornuate uterus in a 64-year-old woman as a case report. The case underwent laparoscopic radical hysterectomy and bilateral iliac lymphadenectomy.

The gross examination of the uterus revealed a bicornuate uterus with a greater horn of $12 \times 9 \times 8 \mathrm{~cm}$ and a smaller horn of $10 \times 3 \mathrm{~cm}$. The cavity of the greater horn showed a neoplastic growth of $10 \mathrm{~cm}$ with infiltration of about $1,8 \mathrm{~cm}$ of the myometrium from whole thickness of $1.9 \mathrm{~cm}$. while the other horn was free of tumor tissue.

The microscopic examination of the uterus revealed G2 endometrioid adenocarcinoma of the endometrium of the greater horn with infiltration of more than $50 \%$ of the myometrium.

In the presence of bicornuate uterus, a bilateral endometrial biopsy should be performed in order to reduce the risk of delayed or missed diagnosis.

The management of a case of bicornuate unicollis uterus with endometrial carcinoma in only one horn is the same as patients with endometrial cancer in single uterus and depends mainly on stage and histological grade of the tumor.

The possibility of existence of a separate uterine cavity should always be considered when endometrial cancer is clinically suspected but pathology fails to confirm the diagnosis. This points out the importance of a careful physical examination and radiographic evaluation in such cases.

(C) 2018 Production and hosting by Elsevier B.V. on behalf of National Cancer Institute, Cairo University. This is an open access article under the CC BY-NC-ND license (http://creativecommons.org/licenses/by-nc-
\end{abstract} nd $/ 4.0 /)$.

\section{Introduction}

The majority of congenital abnormalities of the female genital tract arise from the malformations of the müllerian ducts. The incidence of müllerian duct anomalies is reported to be about $4-5 \%$ in the general population [1], however this incidence is underestimated as most of these cases are asymptomatic and are not diagnosed until they undergo a gynecologic examination or may remain unnoticed.

There are several types of anomalies of müllerian duct development and fusion. The bicornuate uterus, which is a type of these anomalies, results from failure of the müllerian ducts to completely fuse. If the central myometrium extends to the level of

\footnotetext{
Peer review under responsibility of The National Cancer Institute, Cairo University.

* Corresponding author at: Via Floridiana, 30, Rome, RM 00135, Italy.

E-mail addresses: khgab@mans.edu.eg (K. Gaballa), carlacicero@hotmail.it
} (C. Cicero), gianfranco.zannoni@unicatt.it (G. Zannoni). the internal cervical os a bicornuate unicollis uterus is formed and if it extends to the level of the external cervical os a bicornuate bicollis uterus is formed. The latter is distinguished from uterus didelphys as it shows some degree of fusion between the two horns, whereas in classic uterus didelphys the two horns and cervices are completely separated [2].

The presence of endometrial carcinoma in a bicornuate uterus is reported in a few cases especially when a single horn of the uterus is affected [3-9].

In this report, we describe a case of endometrial carcinoma arising in one horn of a bicornuate uterus.

\section{Case report}

A-64-year old hypertensive woman gravida 5, para 2 was presented to health care professional with postmenopausal bleeding. She had 2 cesarean section deliveries and she was menopausal at age of 52. She had a Pap smear test in 2015 which was normal. 
The patient was referred to Policlinico Agostino Gemelli hospital in Rome in September 2015.The patient underwent an abdominopelvic ultrasonography that revealed uterus bicornis, unicollis. Right horn is $53 \times 35 \mathrm{~mm}$ in dimensions, endometrial line 10 $\mathrm{mm}$ thick at the fundus and an intramural myoma of $21 \times 19 \mathrm{~m}$ $\mathrm{m}$. Left horn is $82 \times 81 \mathrm{~mm}$ with heterogeneous endometrial line $9 \mathrm{~mm}$ thick. Right ovary not visualized. Left ovary is normal and no free fluid.

The patient underwent an MRI examination following the pelvic ultrasound that revealed a solid pelvic mass $8 \times 10 \mathrm{~cm}$ on the left side, altered uterine morphology, no lymphadenopathy, no signs of cervical infiltration, normal adnexa and normal Upper abdominal organs (Fig. 1).

The patient underwent a transvaginal sonography (TVS) that showed Uterus bicornis, unicollis. Right horn $70 \times 30 \times 30 \mathrm{~mm}$, hyper echoic and heterogeneous endometrial line of $8 \mathrm{~mm}$ thickness, isthmic myoma $19 \times 19 \mathrm{~mm}$. Left horn $125 \times 73 \times 88 \mathrm{~mm}$ with heterogeneous endometrial line not well delineated from the myometrium.

A diagnostic hysteroscopy was performed following the radiological investigations which revealed a septate vagina, single cervix and a complete uterine septum. The Right uterine cavity showed $1.5 \mathrm{~cm}$ polyp and the left cavity showed thickened friable endometrium. A biopsy was taken from both uterine horns for pathological examination that revealed a G1 endometrioid adenocarcinoma.

The patient was planned for surgery after the biopsy result and underwent laparoscopic hysterectomy, bilateral salpingooophorectomy and frozen section of the uterus and adnexa was done which revealed G2 endometrioid adenocarcinoma of the endometrium with infiltration of more than $50 \%$ of the myometrium so bilateral pelvic lymphadenectomy was completed. The dissected pelvic lymph nodes were sent for frozen section as routinely done in our institute and the result was negative for malignancy so Para-aortic lymphadenectomy was omitted.

The gross examination of the uterus revealed a bicornuate uterus with a greater horn of $12 \times 9 \times 8 \mathrm{~cm}$ and a smaller horn of $10 \times 3 \mathrm{~cm}$ (Fig. 2). The cavity of the greater horn showed a neoplastic growth of $10 \mathrm{~cm}$ with infiltration of about $1,8 \mathrm{~cm}$ of the myometrium from whole thickness of $1.9 \mathrm{~cm}$. No intra or extravascular neoplastic emboli were detected. The cavity of the smaller horn was free of tumor tissue. The cervix was single with normal size and shape. The tubes and ovaries were normal.

The microscopic examination of the uterus revealed G2 endometrioid adenocarcinoma of the endometrium of the greater

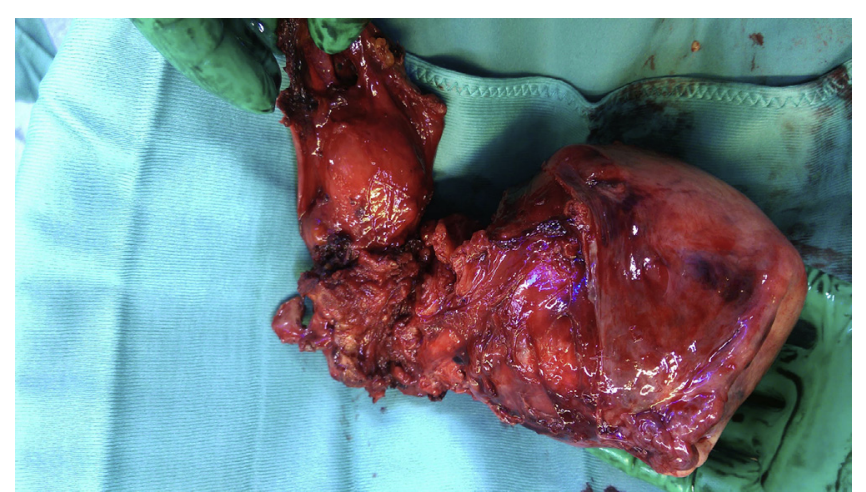

Fig. 2. The gross examination of the uterus revealed a bicornuate uterus with a greater horn of $12 \times 9 \times 8 \mathrm{~cm}$ and a smaller horn of $10 \times 3 \mathrm{~cm}$.

horn with infiltration of more than $50 \%$ of the myometrium. The cervix, tubes, ovaries as well as the pelvic lymph nodes and resection margins were free of tumor tissue.

\section{Discussion}

Müllerian duct anomalies have not been considered as a risk factor in the development of uterine cancers and the coincidence between the presence of uterine malformations and endometrial cancer has never been reported, and in the present literature, there are only few reports of endometrial cancer arising in patients with müllerian abnormalities [3-9].

Most of Müllerian duct anomalies do not reduce the female fertility, and this was obvious in our patient history as she had 2 cesarean section deliveries.

Our case highlights the importance of the presence of uterine anomalies in the differential diagnosis when evaluating postmenopausal bleeding. The prevalence of these anomalies is usually higher than reported due to the asymptomatic nature of some of these cases.

In such type of cases if only one horn of the uterus was biopsied without the other there would have been a delay in the diagnosis of the presence of endometrial cancer. Moreover, many of the described endometrial carcinomas of bicornuate uteri existed in only one horn of the uterus, meaning that there is a $50 \%$ chance of obtaining a biopsy of the benign horn at the time of diagnosis, thereby delaying treatment [3-9].

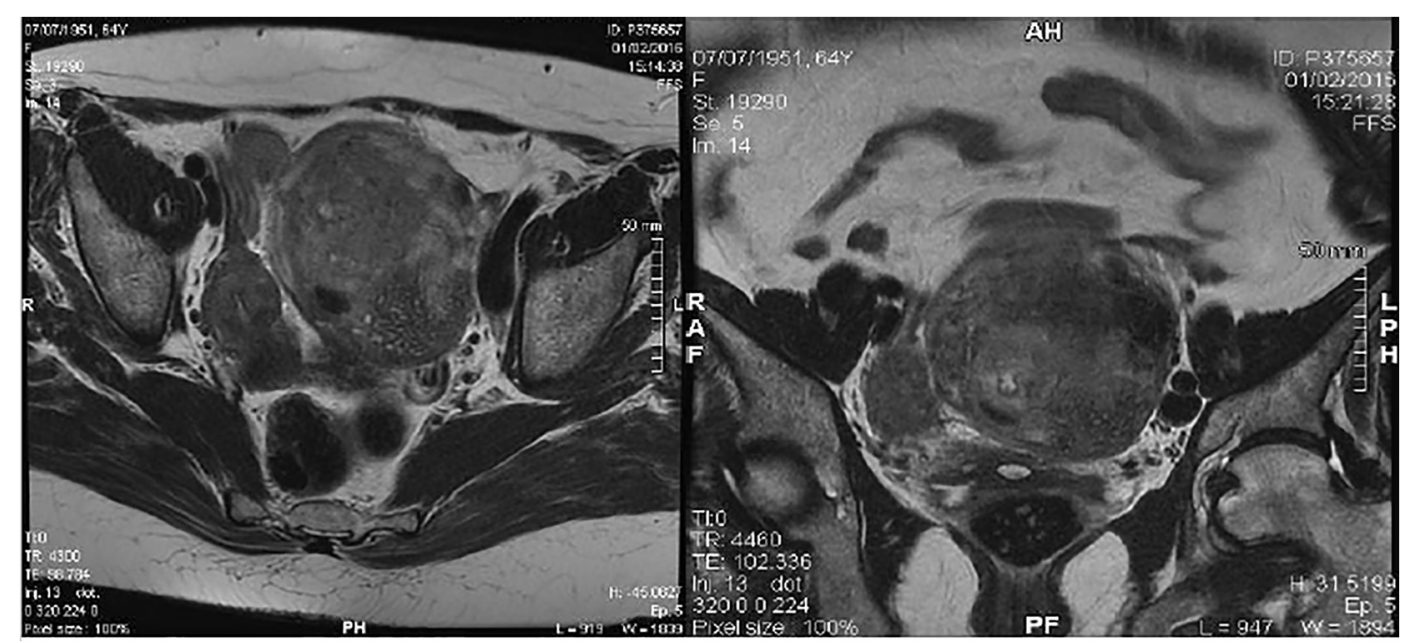

Fig. 1. MRI images showing altered uterine morphology. 
In the presence of bicornuate uterus, a bilateral endometrial biopsy should be performed in order to reduce the risk of delayed or missed diagnosis.

The possibility of existence of a separate uterine cavity should always be considered when endometrial cancer is clinically suspected but pathology fails to confirm the diagnosis. This points out the importance of a careful physical examination and radiographic evaluation in such cases.

\section{Conclusion}

The management of a case of bicornuate unicollis uterus with endometrial carcinoma in only one horn is the same as patients with endometrial cancer in single uterus and depends mainly on stage and histological grade of the tumor, however this management may be more difficult in cases with both horns affected by different histological types and grades of endometrial cancer.

\section{Conflicts of interest}

Authors declare no conflict of interest.

\section{References}

[1] Elford KJ, Spence JE. The forgotten female: pediatric and adolescent gynecological concerns and their reproductive consequences. J Pediatr Adolesc Gynecol 2002;15(2):65-77.

[2] Taylor E, Gomel V. The uterus and fertility. Fertil Steril 2008;89(1):1-16.

[3] Chen CY, Yen MS, Yang MD, Wu YC. Uterus didelphys with adenocarcinoma in the right cavity diagnosed by 2-dimensional sonography and magnetic resonance imaging. J Ultrasound Med 2008;27(12):1802-3.

[4] Dane C, Tatar Z, Dane B, Erqinbas M, Cetin A. A single horn endometrial carcinoma of a uterus bicornis unicollis. J Gynecol Oncol 2009;20(3):195-7.

[5] Eichner E, Simak KA. Uterus didelphys unicollis with adenocarcinoma in one horn and atypical endometrial hyperplasia in the other - case-report. Am J Obstet Gynecol 1981;139(2):222-5.

[6] Grant KB, Sedlacek RL. Uterus didelphys with adenocarcinoma in one fundus - a case report. J Iowa Med Soc 1970;60(5):324-5.

[7] Molpus KL, Puleo JG, Williams AM, Bernal KL, Remmenga SW. Endometrial adenocarcinoma within a single horn of a didelphic uterus - a report of 2 cases. J Reprod Med 2004;49(2):123-5.

[8] Moore JR, Davidson SA, Singh M. Endometrial carcinoma in one horn of a bicornuate uterus. Gynecol Oncol 2004;95(3):729-32.

[9] Herzog TJ, Fry R, Husseinzadeh N. Adenocarcinoma in a single horn of a bicornuate uterus - a case-report. J Reprod Med 1991;36(8):619-21. 